\title{
DEZ ANOS DE UMA NOVA PROPOSTA ACADÊMICA
}

Em 1979, surgiu na Associação dos Docentes da Universidade de São Paulo (Adusp) a idéia de se criar na Universidade um instituto que abrigasse os professores que haviam sido aposentados compulsoriamente pelos Atos Institucionais do Regime Militar. Tempos depois, criou-se uma comissão de professores para retomar essa idéia, que foi enfaticamente defendida durante o II Congresso da USP, em 1984.

No início de 1986, o então reitor da USP José Goldemberg instituiu um Grupo de Estudos oficial para detalhar o projeto de criação do Instituto de Estudos Avançados (IEA) da USP. Os modelos de referência foram o Institute for Advanced Study de Princeton, o Collége de France, o Colégio de México e o Wissenschaftskolleg zu Berlin, entre outras instituições. Em 26 de novembro daquele mesmo ano, o IEA foi criado oficialmente, tendo como primeiro diretor (1986-1988) o historiador Carlos Guilherme Mota, atualmente professor honorário do Instituto.

Durante esses dez primeiros anos de atividade, o Instituto possibilitou à comunidade acadêmica e ao público externo à USP a oportunidade de contato direto com inúmeras personalidades brasileiras e estrangeiras da ciência e da cultura, além de ter produzido propostas para áreas essenciais ao desenvolvimento científico, social e econômico do país.
Algumas dessas propostas destacam-se pela importância estrutural dos seus temas para a modernização do país e por exemplificarem a atuação diferenciada do IEA.

Os programas Educação para Cidadania, Projeto Floram, Fórum Capital-Trabalho e Revisão Constitucional, por exemplo, produziram análises detalhadas e recomendações precisas. Esses estudos subsidiaram debates em outros fóruns, como o Congresso Nacional e várias organizações governamentais e não-governamentais.

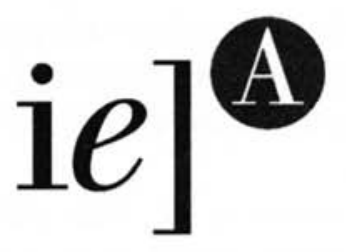

Logotipo do IEA.

Nesse período, dezenas de personalidades contribuíram com o Instituto fazendo

\section{AUTOR}

Mauro Bellesa

Jornalista, assessor de imprensa do Instituto de Estudos Avançados da USP. E-mail: mbellesa@usp.br 
parte de seu grupo de pesquisadores ou como conferencistas convidados. A relação inclui, entre muitos outros, John Kenneth Galbraith, Jürgen Habermas, Christopher Hill, Noam Chomsky, Marcelo Damy, Luiz Hildebrando Pereira da Silva, Robert Darnton, Aníbal Quijano, Aziz Ab'Sáber, Antônio Cândido, Bernard Feld, Raymundo Faoro, William Fyfe, José Paulo Paes, Mílton Santos, Paulo Autran, Jacques Derrida, Mário Molina, Sérgio Costa Ribeiro, Newton da Costa, Edgar Morin, Emília Ferreiro, Oscar Sala, Peter Burke, Otto Gottlieb, Alain Touraine e HansJoaquim Köellreutter.

O IEA caracteriza-se por ser um órgão de integração destinado à pesquisa e discussão, de forma abrangente e interdisciplinar, das questões fundamentais da ciência e da cultura. Tem também a atribuição de realizar, junto com segmentos representativos da sociedade, estudos sobre instituições e políticas públicas (nacionais, estaduais, municipais e até supranacionais). Destacam-se os trabalhos sobre políticas de desenvolvimento da ciência, tecnologia e cultura, bem como sobre o uso social do conhecimento.

Pela natureza de suas atividades, o IEA desempenha papel significativo no incremento do intercâmbio científico e cultural entre a USP e instituições brasileiras e estrangeiras (universidades, organizações governamentais e não-governamentais, entidades científicas e culturais etc.). Isso se dá através de convênios de cooperação e intercâmbio acadêmico ou convites específicos a pesquisadores e intelectuais, brasileiros e estrangeiros, com trabalhos representativos e enriquecedores dos debates realizados no Instituto.
Para atender às suas finalidades, 0 IEA possui estrutura acadêmica diferenciada das demais unidades e institutos da USP. O Instituto não ministra cursos de Graduação ou Pós-Graduação, não possui quadro estável de pesquisadores e não conta com laboratórios, uma vez que a abrangência de seus debates interdisciplinares habilita-o à coordenação de trabalhos experimentais, não à sua execução.

A parceria com outras universidades, entidades científicas, organismos governamentais e instituições civis tem ampliado a variedade dos trabalhos e possibilitado maior interação entre o Instituto e a sociedade. $\mathrm{O}$ estabelecimento de cátedras também se constitui em uma forma diferenciada de criação de postos de pesquisa e intercâmbio científico. Em 1996, o IEA iniciou um novo tipo de atividade: em cada semestre são realizados dois ciclos de conferências temáticas com renomados cientistas.

A participação nas atividades é aberta a pesquisadores e profissionais com projetos relacionados com os temas de trabalho do IEA. A análise dessa confluência temática é feita pelos coordenadores dos agrupamentos de pesquisa. Podem participar brasileiros e estrangeiros, integrantes ou não da USP, portadores ou não de título universitário.

O Conselho Deliberativo é a instância decisória máxima do Instituto. É composto por oito integrantes: seis professores da Universidade (um dos quais é o diretor do Instituto), um representante dos alunos de Pós-Graduação e um representante da sociedade civil. O diretor do IEA preside o Conselho, sendo o responsável pelo cumprimento das deliberações adotadas, além de administrar e coordenar as atividades do Instituto. 


\section{TEMAS DE PESQUISA}

A estrutura acadêmica do IEA é composta por diversos agrupamentos de pesquisa: áreas, grupos de trabalho, programas, cátedras, núcleos e comissões científicas. Alguns são permanentes; outros têm sua duração delimitada pelo tempo necessário para a execução de suas propostas. No final de 1996, os agrupamentos em atividade eram os relacionados a seguir:

\section{ÁREAS}

Assuntos Internacionais - Criada em 1989, a área de Assuntos Internacionais tem como linhas de pesquisa as inserções estratégicas do Brasil no contexto internacional; a política externa brasileira; o papel das organizações internacionais; as questões de fluxos de investimento, comercialização e tecnologia; estratégias de globalização; integração regional e o Mercosul; e políticas do Japão e da China. Ciências Ambientais - As principais preocupações da área de Ciências Ambientais são: desenvolvimento de estudos sobre as alternativas para implementação de soluções coerentes com o desenvolvimento sustentável e análise das mudanças globais. Sob a coordenação da área desenvolvem-se o Projeto Floram, o Grupo de Prevenção de Acidentes Naturais e a Comissão USP de Mudanças Globais.

História Cultural - Os problemas que a globalização econômica e a mundialização da cultura impõem às ciências sociais são o principal tema de pesquisa da área de História Cultural. A reavaliação do papel do Estado nacional merece destaque especial, uma vez que aspectos como a soberania têm de ser repensados num mundo onde as organizações transnacionais são cada vez mais influentes.
Lógica e Teoria da Ciência - O desenvolvimento e aplicações da lógica paraconsistente, inclusive em inteligência artificial, e a axiomatização e estudo dos fundamentos de várias ciências têm sido os destaques das atividades da área de Lógica e Teoria da Ciência. As utilizações da lógica nas humanidades também merecem a atenção da área. Todos esses temas são discutidos em seminários e ciclos de palestras.

Política Científica e Tecnológica - Além de servir como fórum de discussão sobre a orientação científica adotada pela USP em vários setores, a área de Política Científica e Tecnológica desenvolve estudos sobre relações Universidade-empresa, capacitação tecnológica do país em áreas de ponta (espacial, informática, biotecnologia e telecomunicações) e competitividade da indústria brasileira. A atuação das agências de fomento e a legislação de ciência e tecnologia (patentes e incentivos fiscais, por exemplo) também merecem a análise da área.

\section{CÁTEDRAS}

Simón Bolívar - Tendo como principal objetivo a realização de pesquisas sobre as relações culturais, históricas e políticas dos países latino-americanos, a USP e a Fundação Memorial da América Latina criaram no IEA a Cátedra Simón Bolívar, através de convênio assinado em março de 1993. Nos seus três primeiros anos, a cátedra contou com a presença de diversos pesquisadores e organizou vários eventos.

Jaime Cortesão - Criada em maio de 1991, por intermédio de convênio entre a USP e a Comissão Nacional para as Comemorações dos Descobrimentos Portugueses, do Conselho de Ministros de Portugal, a Cátedra Jaime Cortesão agora está vinculada ao Instituto Camões, do Ministério de 
Negócios Estrangeiros daquele país. A cátedra tem propiciado a vinda ao IEA de vários historiadores portugueses e, a partir de 1995 , passou a conceder bolsas para pesquisas em Portugal. Conta também com acervo de 2.500 livros.

Nicolau Copérnico - A USP e a Universidade de Lodz, na Polônia, firmaram convênio em 1995 para a criação no IEA da Cátedra Nicolau Copérnico, para pesquisas nos campos da ciência, cultura e artes, especialmente em torno de questões de interesse comum. Com objetivos semelhantes, foi criada em Lodz a Cátedra José Bonifácio de Andrada e Silva.

Unesco - Para promover um sistema integrado de pesquisa, treinamento, informação e documentação, a USP e a Unesco assinaram convênio para a criação no IEA da Cátedra Unesco de Educação para a Paz, Direitos Humanos, Democracia e Tolerância. A cátedra facilitará a colaboração sub-regional e regional entre pesquisadores de projeção internacional e o corpo docente da USP. A cátedra integrará o Projeto Unitwin Network (rede de universidades) da Unesco.

\section{NÚCLEO}

Nupebraf - Criado em agosto de 1988, em convênio com o Centre de Recherches sur le Brésil Contemporain de l'Ecole Pratique des Hautes Etudes en Sciences Sociales de Paris, o Núcleo de Pesquisa Brasil-França (Nupebraf) dedica-se a promover estudos multidisciplinares sobre as relações culturais entre os dois países. O núcleo possui um banco de dados informatizado com indicações de cerca de $10 \mathrm{mil}$ documentos. Além disso, realiza eventos com personalidades e mantém o Projeto Memória Viva, com gravações de depoimentos.

\section{GRUPOS}

Ciência Cognitiva - O Grupo de Ciência Cognitiva existe desde fins de 1990 e seus principais temas de pesquisa são: fundamentos da ciência cognitiva e psiquiatria cognitiva; computabilidade, incompletude e indecidibilidade na relação cérebro-mente; sistemas dinâmicos, bifurcações e aplicação de biomatemática aos problemas de processamento neuronial; mecânica estatística em redes neuroniais; neurolingüística cognitiva, semiótica e ciência cognitiva; teorias de campo e conexionismo e computação cognitiva.

Estudos Urbanos - O Grupo de Estudos Urbanos foi criado em 1988 com a finalidade de desenvolver e apoiar os estudos urbanos a partir de abordagens interdisciplinares. Entre os seus temas de pesquisa figuram: metropolização no Brasil; degradação de estruturas urbanas; concessão de serviços públicos; história do urbanismo e do planejamento urbano em São Paulo e o espaço geográfico no fim do século 20.

História, Memória e Reconstrução da América Latina - A idéia central do Grupo de História, Memória e Reconstrução da América Latina (em organização) é reunir pesquisadores que vêm se dedicando ao estudo dessas questões. Outra meta é fazer crítica cultural do enfoque que muitos centros de produção cultural estão dando à mundialização. O tema da reconstrução englobará tanto a reorganização dos Estados nacionais em blocos e dos direitos civis até a reestruturação das universidades, escolas e instituições culturais da região.

Prevenção de Acidentes Naturais Instalado em abril de 1995, o Grupo de Estudos de Prevenção de Acidentes Naturais busca integrar e difundir os conhecimentos técnico-científicos de apoio a demandas e políticas públicas de prevenção de 
acidentes. $\mathrm{O}$ grupo tem realizado discussões sobre a previsibilidade de ocorrência e formas de combate a enchentes, escorregamentos e vendavais e estudos para a elaboração de um Mapa de Ameaças Múltiplas no Estado de São Paulo.

Sistemas Complexos - O Grupo de Sistemas Complexos foi instalado em junho de 1994 com o objetivo de ser um fórum permanente de discussão dos trabalhos desenvolvidos por várias equipes da USP. Os sistemas complexos têm sido um tema recorrente em áreas e problemas como reconhecimento de padrões, mecânica celeste, reatores quími$\cos$, mecânica de fluidos, mudança lingüística, séries genéticas, ecossistemas, redes neuroniais e ruptura de materiais.

Teoria Política - O objetivo do Grupo de Teoria Política é o estudo das transformações do Estado e da política para contribuir com o refinamento do instrumental analítico de exame dos processos contemporâneos, especialmente daqueles que incidem no caso do Brasil. São três as linhas de pesquisa do grupo: teoria da democracia, história das idéias e pensamento político brasileiro. $\mathrm{O}$ grupo foi criado em 1989 no Departamento de Ciência Política, sendo transferido para o IEA em janeiro de 1991.

\section{PROGRAMAS}

Educação para a Cidadania - Em 1991, foi criado o Programa Educação para a Cidadania, com dois grupos de estudos: Políticas Públicas de Educação e Paidéia. $\mathrm{O}$ primeiro produziu diagnósticos sobre a situação do sistema educacional brasileiro. O programa prossegue examinando os valores e fins da educação, trabalho iniciado pelo Grupo Paidéia. Um dos temas é o novo paradigma da relação educação-trabalho resultante da crescente valorização do conhecimento nas atividades produtivas.
Projeto Floram - O Projeto Floram estabelece metas ambientais, sociais e econômicas para o florestamento de 20 milhões de hectares (2,3\% do território brasileiro). O projeto foi elaborado em 1989 por uma equipe interdisciplinar do IEA e sua íntegra consta do número nove da revista Estudos Avançados. O projeto é uma proposta para a contribuição brasileira para a fixação do excesso de $\mathrm{CO}^{2}$ em suspensão na atmosfera e com isso ser retardado o risco do efeito estufa. Em julho de 1996, o Floram venceu o prêmio "Esperança do Futuro pela Ciência do Desenvolvimento Sustentável", concedido pela International Union of Air Pollution Prevention and Environmental Protection Associations (Iuappa) em colaboração com a Academia Internacional de Ciências.

\section{COMISSÃO CIENTÍFICA}

Comissão USP de Mudanças Globais $\mathrm{O}$ International Geosphere-Biosphere Programme (IGBP), criado em setembro de 1986 pelo International Council of Scientific Unions (ICSU), conta com uma representação no Brasil sediada no IEA: a Comissão USP de Mudanças Globais, implantada em 1989. O IGBP possui sete temas de pesquisa: química da atmosfera, ecossistemas terrestres, aspectos biosféricos do ciclo hidrológico, interações terraoceano, fluxos nos oceanos, zonas ofóticas e mudanças climáticas do passado. Além de possuir esses agrupamentos de pesquisa, o Instituto colabora com a Academia Brasileira de Ciências (ABC) na organização das sessões regulares da instituição em São Paulo. Nelas são apresentados trabalhos originais de pesquisadores da USP, Unicamp e Unifesp (ex-Escola Paulista de Medicina). 


\section{EVENTOS}

Por ano, os agrupamentos de pesquisa realizam cerca de 130 eventos públicos. $\mathrm{O}$ objetivo desses eventos é apresentar à comunidade acadêmica e à sociedade em geral $o$ andamento e os resultados das atividades do Instituto, bem como propiciar o contato direto com os pesquisadores. Deles podem participar todos os interessados.

Os eventos são bastante diversificados, incluindo palestras, seminários, mesasredondas, debates e congressos. Vários deles possuem caráter internacional. É dada ênfase especial à edição das apresentações realizadas. Esses trabalhos são divulgados na revista Estudos Avançados ou na Coleção Documentos.

\section{REVISTA}

Com perfil editorial bastante singular entre as publicações acadêmicas brasileiras, a revista Estudos Avançados é um periódico interdisciplinar quadrimestral sobre cultura, ciência e tecnologia. Criada em dezembro de 1987, Estudos Avançados conta com 28 edições publicadas e já consolidou sua posição como uma das principais revistas universitárias interdisciplinares de debate científico e cultural.

Além de publicar artigos dos pesquisadores do Instituto e conferencistas convidados, a revista traz textos produzidos fora do IEA sobre questões de relevância nacional e internacional. Os critérios de seleção incluem afinidade com as áreas de trabalho do Instituto, qualidade e oportunidade do artigo. Estudos Avançados procura ser também um fórum de debates sobre problemas socioeconômicos nacionais e latinoamericanos.
Com tiragem média de 2.400 exemplares, Estudos Avançados tem cerca de 400 assinantes, com venda avulsa no IEA, nas livrarias da Editora da USP e em livrarias do Rio de Janeiro e Belo Horizonte. A revista mantém intercâmbio com publicações acadêmicas do Brasil e do Exterior e um programa de doações às principais bibliotecas do país.

\section{CADERNOS}

Com mais de duas centenas de cadernos publicados desde sua criação em novembro de 1989, a Coleção Documentos destina-se à divulgação de working papers, íntegras de palestras apresentadas no Instituto e textos de apoio das discussões travadas nos agrupamentos de pesquisa.

A coleção está dividida em 18 séries normais e seis especiais. As séries correspondem aos agrupamentos de pesquisa atuais e anteriores. A coleção não é periódica. Os cadernos são publicados de acordo com as atividades dos agrupamentos a que estão vinculados.

\section{INFORMATIVO}

Desde 1989, o IEA publica o Informativo Estudos Avançados, que traz matérias, entrevistas e outros dados sobre as atividades dos pesquisadores, agrupamentos de pesquisa e publicações do Instituto, além da programação de eventos abertos ao público no bimestre da edição.

Circula quatro vezes ao ano (mar/abr, mai/jun, ago/set, out/dez), com oito páginas e tiragem de sete mil exemplares. Informativo Estudos Avançados é distribuído gratuitamente a todos os interessados cadastrados na mala direta do Instituto. 


\section{PROGRAMA DE RÁDIO}

Todos os sábados, às $15 \mathrm{~h}$, a Rádio USP FM (93,7 Mhz) transmite o programa Uma Janela Para o Mundo, produzido pelo IEA com o intuito de compartilhar com o grande público as idéias elaboradas e debatidas pelos integrantes do Instituto.

São apresentadas entrevistas com pesquisadores e conferencistas convidados, que abordam todos os temas em discussão no IEA. Cópias de todos os programas transmitidos podem ser encomendadas no Centro de Documentação do Instituto.

\section{INTERNET}

Informações atualizadas sobre as pesquisas e eventos do Instituto podem ser consultadas na home page http://www.usp.br/iea. Dado o crescimento exponencial de usuários da Internet e as facilidades que ela propicia para a divulgação acadêmica, futuramente devem ser aprimorados os serviços prestados via World Wide Web (WWW), o sistema multimídia da rede, com a disponibilização de textos de artigos e conferências e a edição de boletins temáticos, entre outros serviços possíveis.

\section{CENTRO DE DOCUMENTAÇÃO}

O Centro de Documentação do IEA é constituído por uma biblioteca de referência, cerca de 50 títulos de periódicos, vídeos de 94 conferências e fitas de áudio de 650 eventos e 150 programas de rádio, além de uma coleção de imagens de satélite forneci- das regularmente pelo Instituto Nacional de Pesquisas Espaciais (Inpe).

Voltado preferencialmente ao atendimento dos pesquisadores do Instituto, o acervo também pode ser consultado por outros interessados, desde que agendem a visita. As imagens de satélite do território brasileiro podem ser vistas no local. Os vídeos são emprestados e as fitas de áudio, reproduzidas por encomenda.

\section{CONSELHO DELIBERATIVO}

Desde 1994, o professor Umberto Cordani, titular do Instituto de Geociências, é o diretor do IEA, tendo sucedido ao professor Jacques Marcovitch, que dirigiu o Instituto de 1989 a 1993. O vice-diretor é o professor Alfredo Bosi, titular de Literatura Brasileira da Faculdade de Filosofia, Letras e Ciências Humanas. Além dos professores Cordani e Bosi, também integram o Conselho Deliberativo os professores da USP Henrique Fleming (Instituto de Física), Maria Victória Benevides (Faculdade de Educação), Renato Migliorini (Faculdade de Medicina de Ribeirão Preto) e Walter Colli (Instituto de Química); Carlos Takiya, representante dos alunos de Pós-Graduação; e o administrador e ex-deputado estadual Fernando Leça, representante da sociedade civil.

O IEA fica na Av. Prof. Luciano Gualberto, Travessa J, 374, térreo, Cidade Universitária, CEP 05508-900 - São Paulo, SP. Telefones (011) 818-3919 e 818-4442. Fax: (011) 211-9563. E-mail: iea@org.usp.br. Home page: http//www.usp.br/iea. 
Resumo: O Instituto de Estudos Avançados IEA é um orgão da USP destinado à pesquisa e discussão, de forma abrangente e interdisciplinar, de questōes científicas e culturais. Em seus dez anos de existência possibilitou à comunidade acadêmica e ao público externo à USP o contato com inúmeros cientistas e personalidades brasileiros e estrangeiros, além de ter produzido propostas para o desenvolvimento científico, social e econômico do pais.

Palavras-chave: Instituto de Estudos Avançados, pesquisa, ciência, cultura, USP
Abstract: The Institute of Advanced Studies IAS (Instituto de Estudos Avançados - IEA) is an organism of the University of São Paulo which promotes broad and interdisciplinary research and discussion in the scientific and cultural fields. During its decade of existence it has offered to the academic community and to the public in general the possibility of being in contact with several Brazilian and foreign scientists and celebrities. It has also elaborated propositions for the economic, social, and scientific development of Brazil.

Key-words: Institute of Advanced Studies, research, science, culture, USP 